\title{
Mapping Global Solar Radiation from Long-Term Satellite Data in the Tropics Using an Improved Model
}

\author{
S. Janjai, I. Masiri, S. Pattarapanitchai, and J. Laksanaboonsong \\ Solar Energy Research Laboratory, Department of Physics, Faculty of Science, Silpakorn University, Nakhon Pathom 73000, Thailand \\ Correspondence should be addressed to S. Janjai; serm@su.ac.th
}

Received 3 January 2013; Revised 28 February 2013; Accepted 1 March 2013

Academic Editor: Manuel Antón

Copyright (c) 2013 S. Janjai et al. This is an open access article distributed under the Creative Commons Attribution License, which permits unrestricted use, distribution, and reproduction in any medium, provided the original work is properly cited.

\begin{abstract}
This paper presents an improved model and its application for mapping global solar radiation from satellite data in the tropics. The model provides a more complete description of the absorption and scattering of solar radiation in the earth-atmosphere system as compared to the earlier models. The study is conducted in the tropical environment of Thailand. Digital data from the visible channel of GMS4, GMS5, GOES9, and MTSAT-1R satellites collected during a 15-year period (1995-2009) are used as a main input to the model. Satellite gray levels are converted into earth-atmospheric reflectivity and used to estimate the cloud effect. The absorption of solar radiation due to water vapour is computed from precipitable water derived from ambient temperature and relative humidity. The total ozone column data from TOMS/EP and OMI/AURA satellites are used to compute solar radiation absorption by ozone. The depletion of solar radiation due to aerosol is estimated from visibility data. In order to test its performance, the model is employed to calculate monthly average daily global solar radiation at 36 solar monitoring stations across the country. It is found that solar radiation calculated from the model and that obtained from the measurement are in good agreement, with a root mean square difference of $5.3 \%$ and a mean bias difference of $0.3 \%$. The model is used to calculate the monthly average daily global solar radiation over the entire country, and results are displayed as monthly and yearly maps. These maps reveal that the geographical distribution of solar radiation in Thailand is strongly influenced by the tropical monsoons and local geographical features.
\end{abstract}

\section{Introduction}

Information on the amount of solar radiation at the earth surface is essential for solar energy applications and atmospheric research. Ideally, such information should be obtained from a dense network of solar radiation monitoring stations covering an area of interest. However, in practice the number of stations in existing networks is generally too sparse to provide sufficient data for users.

Geostationary meteorological satellites record backscattered solar radiation from the earth-atmosphere system at high temporal frequencies, therefore providing a means to estimate surface solar irradiance. In the past 30 years, some models have been proposed to derive solar radiation from satellite data [1-23]. These models have different degrees of complexity and accuracy. Furthermore, most of these models were developed for mid and high latitude zones. Published reports on satellite models for the tropics are very limited. Although we have developed a satellite-based solar radiation model for calculating solar radiation in a tropical environment of Thailand [24], several assumptions were made in the original paper to simplify the calculations. Additionally, the model validation was carried out against only four ground stations recording solar radiation.

The objective of this work is to improve our previous model by accounting for the effect of the absorption of solar radiation in the upwelling path as well as in multiple scattering between the ground and the atmosphere in the satellite band. The methods for calculating absorption of solar radiation by water vapour and ozone have also been improved. This improved model is validated against measured solar radiation from 36 stations in Thailand. After the validation, the model is employed to map solar radiation over Thailand. The radiation maps obtained from this work will represent the solar radiation climatology of this country.

\section{Methodology}

This section consists of four parts, namely, processing of satellite data, design of the improved model, and calculation 


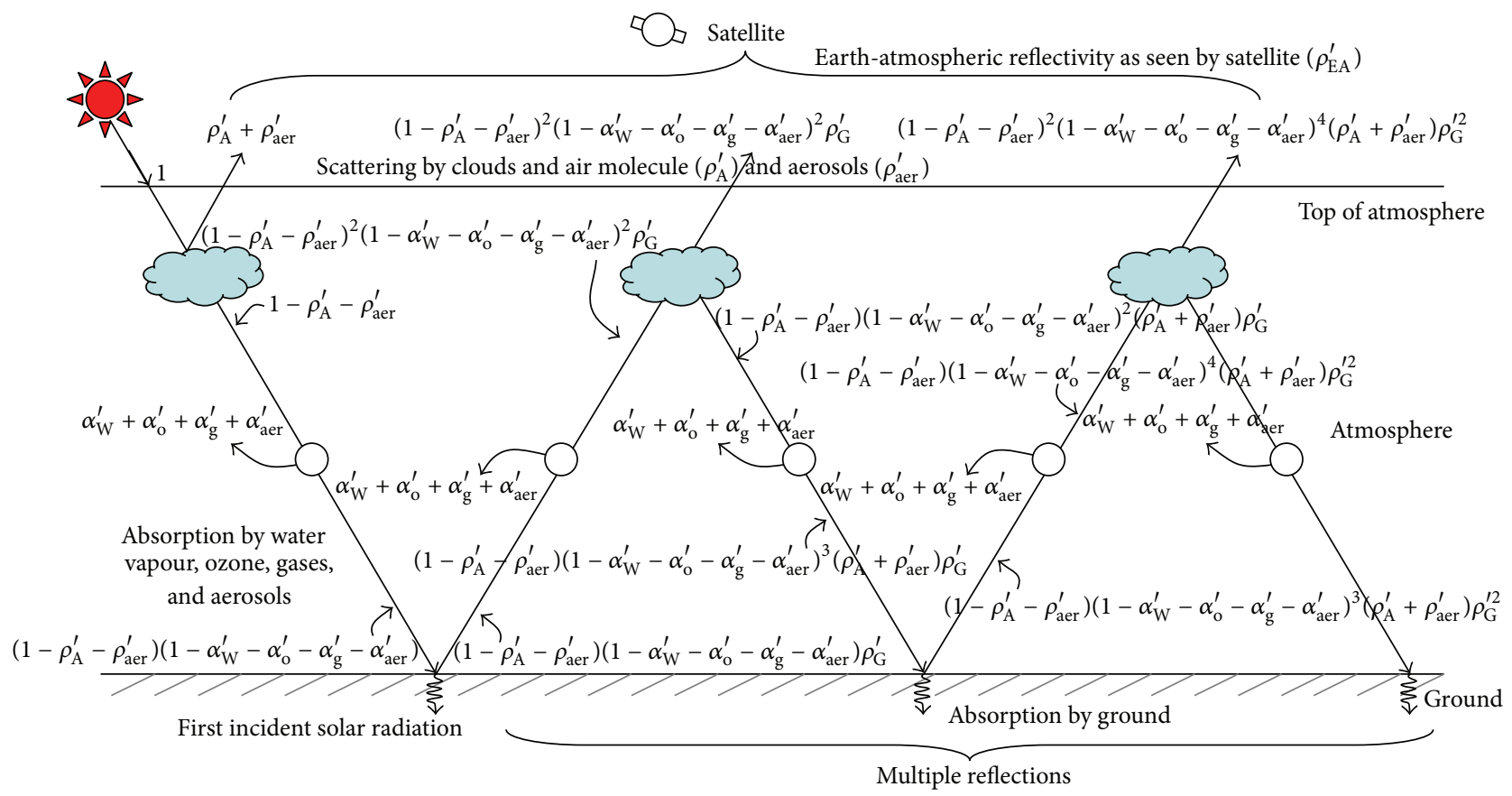

FIGURE 1: Schematic diagram of the radiation budget as seen by the satellite in the improved model.

of model parameters, model validation and solar radiation mapping. The details of each part are described as follows.

2.1. Processing of Satellite Data. The satellite images used in this work are obtained from 4 geostationary satellites, namely, GMS4, GMS5, GOES9, and MTSAT-1R. The satellites GMS4, GMS5 and MTSAT-1R are operated by Japanese Meteorological Agency (JMA) and GOES9 satellite is operated by National Oceanic and Atmospheric Administration (NOAA), USA, incorporated with JMA. The satellite data are obtained from JMA. The periods of the satellite data and the wavelength bands used in this project are shown in Table 1.

Normally, the satellites give hourly image data. However, for each day only the data from $8: 30$ AM to $4: 30$ PM are used in this work. The early morning and late afternoon data are not used, due to their low quality caused by low brightness and non-Lambertian reflection. The total period of data used is 15 years (1995-2009) with approximately 35,600 images.

When displayed as images, the digital data cover the entire area of Thailand with a spatial resolution of $3 \times 3 \mathrm{~km}^{2}$. These images are transformed into a cylindrical projection, being linear in latitude and longitude. They are subsequently navigated using features of the coastline as a reference. Each image consists of a matrix of $500 \times 800$ pixels representing solar radiation reflected from the earth-atmosphere system in the form of gray levels (0-255). The values of the gray levels are transformed into the pseudo-reflectivity $\left(\rho_{\mathrm{SAT}}^{i}\right)$ using calibration tables provided by the satellite agencies. In the final step, the pseudo-reflectivity is divided by the cosine of the local solar zenith angle at each pixel so as to obtain earth-atmospheric albedo $\left(\rho_{\mathrm{EA}}^{\prime}\right)$. The values of $\rho_{\mathrm{EA}}^{\prime}$ are used in the satellite-based radiation model.
TABLE 1: Periods and wavelength bands of the satellite data used in this project.

\begin{tabular}{lcc}
\hline Satellite & Periods & $\begin{array}{c}\text { Wavelength bands } \\
\text { of visible data }\end{array}$ \\
\hline GMS4 & January-May, 1995 & $0.50-0.75 \mu \mathrm{m}$ \\
GMS5 & June, 1995-May, 2003 & $0.55-0.90 \mu \mathrm{m}$ \\
GOES9 & June, 2003-July, 2005 & $0.50-0.75 \mu \mathrm{m}$ \\
MTSAT-1R & August, 2005-December, 2009 & $0.55-0.90 \mu \mathrm{m}$ \\
\hline
\end{tabular}

2.2. Improvement of a Satellite-Based Solar Radiation Model. A satellite-based solar radiation model proposed by Janjai et al. [24] is modified for the calculation of surface global solar radiation from satellite data. The improved model considers the depletion of solar radiation due to clouds, ozone, aerosols, water vapour, and trace gases in the atmosphere, for both the upwelling and downwelling paths of solar radiation. The multiple reflections between the atmosphere and the ground are also taken into account in this model. The absorption and scattering of solar radiation in the earth-atmosphere system as used in the model are schematically shown in Figure 1.

Consider a unit of the downwelling solar radiation entering the earth atmosphere, part of which is scattered to the outer space by clouds, air molecules, and aerosols (see Figure 1). The scattering due to clouds, air molecules, and aerosols in the atmosphere can be represented in terms of reflection coefficients $\left(\rho_{\mathrm{A}}^{\prime}+\rho_{\mathrm{aer}}^{\prime}\right)$; hence the remaining portion of radiation in its path is $1-\rho_{\mathrm{A}}^{\prime}-\rho_{\mathrm{aer}}^{\prime}$. Note that the scattering of clouds and air molecules is represented by one coefficient, called atmospheric reflectance $\left(\rho_{\mathrm{A}}^{\prime}\right)$. This is because the scattering by air molecules occurs both above and 
below cloud layers and it is not possible to decompose $\rho_{\mathrm{A}}^{\prime}$ as a sum of Rayleigh scattering reflectance and cloud reflectance, due to the nonlinear interaction between air molecules and clouds. From this point, the rest of the downwelling radiation is absorbed by ozone, gases, water vapour, and aerosols with the absorption coefficients of $\alpha_{\mathrm{o}}^{\prime}, \alpha_{\mathrm{g}}^{\prime}, \alpha_{\mathrm{w}}^{\prime}$, and $\alpha_{\mathrm{aer}}^{\prime}$, respectively. The remaining solar radiation arriving at the ground is $(1-$ $\left.\rho_{\mathrm{A}}^{\prime}-\rho_{\mathrm{aer}}^{\prime}\right) \times\left(1-\alpha_{\mathrm{w}}^{\prime}\right)\left(1-\alpha_{\mathrm{o}}^{\prime}\right)\left(1-\alpha_{\mathrm{g}}^{\prime}\right)\left(1-\alpha_{\mathrm{aer}}^{\prime}\right)$, but the terms $\left(1-\alpha_{\mathrm{w}}^{\prime}\right)\left(1-\alpha_{\mathrm{o}}^{\prime}\right)\left(1-\alpha_{\mathrm{g}}^{\prime}\right)\left(1-\alpha_{\mathrm{aer}}^{\prime}\right)$ can be approximated as $\left(1-\alpha_{\mathrm{w}}^{\prime}-\alpha_{\mathrm{o}}^{\prime}-\alpha_{\mathrm{aer}}^{\prime}-\alpha_{\mathrm{g}}^{\prime}\right)$. As a result, the remaining radiation can be written as $\left(1-\rho_{\mathrm{A}}^{\prime}-\rho_{\mathrm{aer}}^{\prime}\right)\left(1-\alpha_{\mathrm{w}}^{\prime}-\alpha_{\mathrm{o}}^{\prime}-\alpha_{\mathrm{aer}}^{\prime}-\alpha_{\mathrm{g}}^{\prime}\right)$. This solar radiation is then reflected back to the atmosphere by the ground with the surface albedo of $\rho_{\mathrm{G}}^{\prime}$. Part of the reflected solar radiation is again absorbed by aerosols and scattered by clouds, air molecules, and aerosols. Hence, part of radiation leaving the atmosphere to the outer space from the first incident solar radiation is written as $\left(1-\rho_{\mathrm{A}}^{\prime}-\rho_{\mathrm{aer}}^{\prime}\right)^{2} \times$ $\left(1-\alpha_{\mathrm{w}}^{\prime}-\alpha_{\mathrm{o}}^{\prime}-\alpha_{\mathrm{aer}}^{\prime}-\alpha_{\mathrm{g}}^{\prime}\right)^{2} \rho_{\mathrm{G}}^{\prime}$. The remaining portion is reflected back to the ground by clouds, air molecules, and aerosols. Then the process is repeated. The sum of all solar radiation leaving the atmosphere to the outer space is called earthatmospheric reflectivity $\left(\rho_{\mathrm{EA}}^{\prime}\right)$. It is observed by the satellite and can be written as

$$
\begin{aligned}
\rho_{\mathrm{EA}}^{\prime}= & \rho_{\mathrm{A}}^{\prime}+\rho_{\mathrm{aer}}^{\prime}+\left(1-\rho_{\mathrm{A}}^{\prime}-\rho_{\mathrm{aer}}^{\prime}\right)^{2} \\
& \times\left(1-\alpha_{\mathrm{w}}^{\prime}-\alpha_{\mathrm{o}}^{\prime}-\alpha_{\mathrm{g}}^{\prime}-\alpha_{\mathrm{aer}}^{\prime}\right)^{2} \rho_{\mathrm{G}}^{\prime}+\left(1-\rho_{\mathrm{A}}^{\prime}-\rho_{\mathrm{aer}}^{\prime}\right)^{2} \\
& \times\left(1-\alpha_{\mathrm{w}}^{\prime}-\alpha_{\mathrm{o}}^{\prime}-\alpha_{\mathrm{g}}^{\prime}-\alpha_{\mathrm{aer}}^{\prime}\right)^{4} \\
& \times\left(\rho_{\mathrm{A}}^{\prime}+\rho_{\mathrm{aer}}^{\prime}\right) \rho_{\mathrm{G}}^{\prime 2}+\left(1-\rho_{\mathrm{A}}^{\prime}-\rho_{\mathrm{aer}}^{\prime}\right)^{2} \\
& \times\left(1-\alpha_{\mathrm{w}}^{\prime}-\alpha_{\mathrm{o}}^{\prime}-\alpha_{\mathrm{g}}^{\prime}-\alpha_{\mathrm{aer}}^{\prime}\right)^{6} \\
& \times\left(\rho_{\mathrm{A}}^{\prime}+\rho_{\mathrm{aer}}^{\prime}\right)^{2} \rho_{\mathrm{G}}^{\prime 3}+\cdots \\
\rho_{\mathrm{EA}}^{\prime}= & \rho_{\mathrm{A}}^{\prime}+\rho_{\mathrm{aer}}^{\prime}+\frac{\left(1-\rho_{\mathrm{A}}^{\prime}-\rho_{\mathrm{aer}}^{\prime}\right)^{2}}{\left(\rho_{\mathrm{A}}^{\prime}+\rho_{\mathrm{aer}}^{\prime}\right)} \\
& \times \sum_{n=1}^{\infty}\left[\left(1-\alpha_{\mathrm{w}}^{\prime}-\alpha_{\mathrm{o}}^{\prime}-\alpha_{\mathrm{g}}^{\prime}-\alpha_{\mathrm{aer}}^{\prime}\right)^{2}\left(\rho_{\mathrm{A}}^{\prime}+\rho_{\mathrm{aer}}^{\prime}\right) \rho_{\mathrm{G}}^{\prime}\right]^{n}
\end{aligned}
$$

or

$$
\begin{aligned}
\rho_{\mathrm{EA}}^{\prime}= & \rho_{\mathrm{A}}^{\prime}+\rho_{\mathrm{aer}}^{\prime} \\
& +\frac{\left(1-\rho_{\mathrm{A}}^{\prime}-\rho_{\mathrm{aer}}^{\prime}\right)^{2}\left(1-\alpha_{\mathrm{w}}^{\prime}-\alpha_{\mathrm{o}}^{\prime}-\alpha_{\mathrm{g}}^{\prime}-\alpha_{\mathrm{aer}}^{\prime}\right)^{2} \rho_{\mathrm{G}}^{\prime}}{1-\left(\rho_{\mathrm{A}}^{\prime}+\rho_{\mathrm{aer}}^{\prime}\right)\left(1-\alpha_{\mathrm{w}}^{\prime}-\alpha_{\mathrm{o}}^{\prime}-\alpha_{\mathrm{g}}^{\prime}-\alpha_{\mathrm{aer}}^{\prime}\right)^{2} \rho_{\mathrm{G}}^{\prime}} .
\end{aligned}
$$

The variables with "prime" denote their values in the satellite band, for example, $0.55-0.90 \mu \mathrm{m}$ for GMS5 and MTSAT-1R.

Rearranging (2) yields

$$
\rho_{\mathrm{A}}^{\prime}=\frac{A-A C+A B C+B C^{2}}{C-1+B C+A C},
$$

where

$$
\begin{gathered}
A=\rho_{\mathrm{aer}}^{\prime}-\rho_{\mathrm{EA}}^{\prime}, \\
B=1-\rho_{\mathrm{aer}}^{\prime}, \\
C=\left(1-\alpha_{\mathrm{w}}^{\prime}-\alpha_{\mathrm{o}}^{\prime}-\alpha_{\mathrm{aer}}^{\prime}-\alpha_{\mathrm{g}}^{\prime}\right)^{2} \rho_{\mathrm{G}}^{\prime} .
\end{gathered}
$$

From (3), $\rho_{\mathrm{EA}}^{\prime}$ is obtained from satellite data and $\rho_{\mathrm{aer}}^{\prime}, \alpha_{\mathrm{w}}^{\prime}$, and $\alpha_{\mathrm{g}}^{\prime}$ can be derived from ground-based measurements. The surface albedo $\rho_{\mathrm{G}}^{\prime}$ and ozone absorption coefficient $\alpha_{\mathrm{o}}^{\prime}$ can be derived from satellite data. The method for deriving these coefficients is explained in the next section. Therefore, values of $\rho_{\mathrm{A}}^{\prime}$ can be calculated from (3). In the next step $\rho_{\mathrm{A}}^{\prime}$, which is in satellite band, is converted into broadband atmospheric albedo $\left(\rho_{\mathrm{A}}: 0.3-3.0 \mu \mathrm{m}\right)$ using empirical formula explained in the next section. Then broadband atmospheric albedo $\left(\rho_{\mathrm{A}}\right)$ is used to calculate broadband atmospheric transmittance, which is expressed as

$$
\tau=\frac{\left(1-\rho_{\mathrm{A}}-\rho_{\mathrm{aer}}\right)\left(1-\alpha_{\mathrm{w}}-\alpha_{\mathrm{o}}-\alpha_{\mathrm{aer}}-\alpha_{\mathrm{g}}\right)}{1-\left(\rho_{\mathrm{A}}+\rho_{\mathrm{aer}}\right)\left(1-\alpha_{\mathrm{w}}-\alpha_{\mathrm{o}}-\alpha_{\mathrm{aer}}-\alpha_{\mathrm{g}}\right)^{2} \rho_{\mathrm{G}}},
$$

where $\tau$ is broadband transmittance of the atmosphere. The unprimed variables denote the scattering and absorption of solar radiation by the atmosphere constituents in broadband $(0.3-3.0 \mu \mathrm{m})$. The term $\left(1-\rho_{\mathrm{A}}-\rho_{\mathrm{aer}}\right)\left(1-\alpha_{\mathrm{w}}-\alpha_{\mathrm{o}}-\right.$ $\left.\alpha_{\text {aer }}-\alpha_{\mathrm{g}}\right)$ represents the first incident solar radiation on the ground (see Figure 1). The denominator term represents the multiple reflections between the ground and the atmosphere. The values of $\rho_{\mathrm{G}}, \rho_{\mathrm{aer}}, \alpha_{\mathrm{aer}}, \alpha_{\mathrm{o}}$, and $\alpha_{\mathrm{w}}$ can be calculated using ground- and satellite-based data as explained in the next section. Therefore, values of $\tau$ are obtained from (5). These values are finally employed to compute solar radiation incident on the ground using the following equation:

$$
H=\tau H_{0},
$$

where $H$ is daily radiation on the earth surface and $H_{0}$ is extraterrestrial daily irradiation. $H_{0}$ was calculated by using the formula reported in Iqbal [25]. In calculating $H_{0}$ from this formula, a solar constant of $1366.1 \mathrm{~W} / \mathrm{m}^{2}$ is used [26]. All parameters of the model are determined using monthly average daily basis.

\subsection{Calculation of Model Parameters}

2.3.1. Surface Albedo $\left(\rho_{G}\right)$. The surface albedo is estimated from satellite images collected at $12: 30 \mathrm{~h}$ local time. For each month, digital data of rectified images are examined and pixels with the lowest gray level value are selected to create the cloud-free composite image for that month. All cloudfree composite images are then transformed into cloud-free earth-atmospheric reflectivity by using the conversion table. The effect of the atmospheric reflectivity is removed from the cloud-free earth-atmospheric albedo by using $6 \mathrm{~S}$ radiative transfer model $[27,28]$. 
2.3.2. Absorption Coefficient of Water Vapour. The amount of atmospheric water vapour is usually quantified as a thickness (in $\mathrm{cm}$ ) of precipitable water. The absorption coefficient of water vapour can be determined by the followings equations:

(i) in satellite band:

$$
\alpha_{\mathrm{w}}^{\prime}=1-\frac{\int_{\lambda_{1}}^{\lambda_{2}} I_{0 \lambda} \tau_{\mathrm{w} \lambda} d \lambda}{\int_{\lambda_{1}}^{\lambda_{2}} I_{0 \lambda} d \lambda},
$$

(ii) in broadband:

$$
\alpha_{\mathrm{w}}=1-\frac{\int_{0.3 \mu \mathrm{m}}^{3.0 \mu \mathrm{m}} I_{0 \lambda} \tau_{\mathrm{w} \lambda} d \lambda}{\int_{0.3 \mu \mathrm{m}}^{3.0 \mu \mathrm{m}} I_{0 \lambda} d \lambda},
$$

where $I_{0 \lambda}$ is extraterrestrial spectral irradiance, $\tau_{\mathrm{w} \lambda}$ is spectral transmittance of water vapour, $\alpha_{\mathrm{w}}^{\prime}$ is absorption coefficient of water vapour in the satellite band, $\alpha_{\mathrm{w}}$ is absorption coefficient of water vapour in the broadband, and $\lambda_{1}$ and $\lambda_{2}$ are wavelength bands of the satellite. Transmittance of water vapour is determined using the formula of Leckner [29]. In order to determine this transmittance, precipitable water is required. Though precipitable water data are available from satellites such as MODIS, there are a lot of missing data from the satellite over this region and the spatial resolution of the data is relatively low. Therefore, in this work ambient air temperature and relative humidity data collected at 85 meteorological stations over Thailand are used to estimate precipitable water. The measurements of the temperature and relative humidity follow the guideline of WMO (World Meteorological Organization). As temperature and relative humidity are measured every 3-hour interval, they are interpolated to obtain hourly data. Only the data obtained during day time are used to calculate precipitable water employing the formula proposed by Janjai et al. [24]. In our previous work, variation of precipitable water with latitude was used to determine its values over the country. This approach created some uncertainties due to non-systematic spatial distribution of precipitable water in some areas. In this work, the values of precipitable water at 85 stations are extrapolated to obtain the values of precipitable water covering the entire area of the country. This approach is more realistic than the previous one.

2.3.3. Absorption Coefficient of Ozone. In this work, the absorption coefficients due to ozone were calculated from the following equations:

(i) in satellite band:

$$
\alpha_{\mathrm{o}}^{\prime}=1-\frac{\int_{\lambda_{1}}^{\lambda_{2}} I_{0 \lambda} \tau_{\mathrm{o} \lambda} d \lambda}{\int_{\lambda_{1}}^{\lambda_{2}} I_{0 \lambda} d \lambda},
$$

(ii) in broadband:

$$
\alpha_{\mathrm{o}}=1-\frac{\int_{0.3 \mu \mathrm{m}}^{3.0 \mu \mathrm{m}} I_{0 \lambda} \tau_{\mathrm{o} \lambda} d \lambda}{\int_{0.3 \mu \mathrm{m}}^{3.0 \mu \mathrm{m}} I_{0 \lambda} d \lambda},
$$

where $\alpha_{\mathrm{o}}^{\prime}$ is absorption coefficient of ozone in the satellite band, $\alpha_{\mathrm{o}}$ is the absorption coefficient of ozone in broadband, and $\tau_{\mathrm{o} \lambda}$ is spectral transmittance of ozone. Spectral transmittance of ozone was calculated using a model reported by Iqbal [25]. In a previous study [24], total ozone column at Bangkok was used as representative of the total ozone column over the country. In this work, the level 3 total ozone column from TOMS/EP and OMI/Aura satellites is used for the calculation of the spectral transmittance coefficient. This is because the ground-based total ozone column measurements in this region are very limited and the accuracy of the satellitederived total ozone column is relatively good [30].

2.3.4. Absorption Coefficient of Atmospheric Gases. In our previous work, this coefficient was included in the calculation of the absorption by water vapour. In this work, a relationship described by Leckner [29] for spectral transmission of gases $\left(\tau_{\mathrm{g} \lambda}\right)$ after absorption by carbon dioxide, oxygen, and other trace gases is used to calculate the spectral transmittance. The absorption coefficient of gases is calculated from the spectral transmittance as follows:

(i) in satellite band:

$$
\alpha_{\mathrm{g}}^{\prime}=1-\frac{\int_{\lambda_{1}}^{\lambda_{2}} I_{0 \lambda} \tau_{\mathrm{g} \lambda} d \lambda}{\int_{\lambda_{1}}^{\lambda_{2}} I_{0 \lambda} d \lambda},
$$

(ii) in broadband:

$$
\alpha_{\mathrm{g}}=1-\frac{\int_{0.3 \mu \mathrm{m}}^{3.0 \mu \mathrm{m}} I_{0 \lambda} \tau_{\mathrm{g} \lambda} d \lambda}{\int_{0.3 \mu \mathrm{m}}^{3.0 \mu \mathrm{m}} I_{0 \lambda} d \lambda},
$$

where $\alpha_{\mathrm{g}}^{\prime}$ is absorption coefficient of gases in satellite band and $\alpha_{\mathrm{g}}$ is absorption coefficient of gases in broadband.

2.3.5. Solar Radiation Depletion by Aerosols. Aerosols are fine solid or liquid particles in a state of suspension in the atmosphere. They play an important role in depletion of solar radiation within a polluted atmosphere. Aerosol properties in the atmosphere can be measured by using ground-based instruments such as sunphotometers. However, it is costly to deploy such instruments over a large area.

Although, the aerosol optical depth (AOD) derived from satellite such as MODIS can be used to quantify the effect of aerosols on solar radiation, the uncertainty of satellitederived AOD is significantly high, compared to groundbased measurements in this region [31]. In addition, the spatial resolution of the satellite-derived AOD is relatively low and the periods of the available AOD data do not match with this study period (1995-2009). Therefore, in this study we use the visibility to quantify the effect of aerosols on solar radiation. Visibility data visually observed at 85 meteorological stations across the country are used and interpolated to cover the entire areas of the country. A relationship between the visibility and the coefficient of the depletion of solar radiation due to aerosols $\left(D_{\text {aer }}\right)$, developed 
TABLE 2: Details of the stations and their data.

\begin{tabular}{lccc}
\hline Stations & Latitude & Longitude & Period of data \\
\hline Chiang Mai & $18.78^{\circ} \mathrm{N}$ & $98.98^{\circ} \mathrm{E}$ & Jan., 1995-Dec., 2008 \\
Ubon Ratchathani & $15.25^{\circ} \mathrm{N}$ & $104.87^{\circ} \mathrm{E}$ & Jan., 1995-Dec., 2008 \\
Nakhon Pathom & $13.82^{\circ} \mathrm{N}$ & $100.04^{\circ} \mathrm{E}$ & Jan., 1995-Dec., 2008 \\
Songkhla & $7.20^{\circ} \mathrm{N}$ & $100.60^{\circ} \mathrm{E}$ & Jan., 1995-Dec., 2008 \\
\hline
\end{tabular}

by Janjai et al. [24], is used in this work. This coefficient is defined as the ratio of the difference between clear sky solar radiation without aerosols and actual clear sky radiation with aerosols. This relationship is written as

$$
D_{\mathrm{aer}}=0.3631-0.0222(\mathrm{VIS})+0.0003(\mathrm{VIS})^{2}
$$

where $D_{\text {aer }}$ is the solar radiation depletion coefficient due to aerosols and VIS is visibility in $\mathrm{km}$.

The depletion of solar radiation caused by aerosols $\left(D_{\text {aer }}\right)$ is a result of absorption and scattering processes. To determine the proportion between the scattering and absorption effects, single scattering albedo data (SSA) is needed. Although SSA data are available from OMI/Aura satellite, this SSA is derived for UV wavelength $(320 \mathrm{~nm})$ and the data are available from 2004, which do not meet the requirements of this work. As there are a lot of sunphotometer stations of AERONET (Aerosol Robotic Network) of NASA in East Asia, including four stations in Thailand, SSA data from 82 stations located across East Asia are used to determine the proportion between the scattering and absorption caused by aerosols over Thailand. The absorption and scattering fractions are interpolated over the entire areas of the country. Using these fractions, the scattering coefficient $\left(\rho_{\text {aer }}\right)$ and absorption coefficients $\left(\alpha_{\text {aer }}\right)$ are determined. This method is more realistic than that used in the previous model.

2.3.6. Broadband Atmospheric Reflectivity $\left(\rho_{A}\right)$. The broadband atmospheric reflectivity is required for the calculation of the surface solar radiation (5) and (6). However, the satellite gives only the satellite band reflectivity $\left(\rho_{\mathrm{A}}^{\prime}\right.$ in (3)). We proposed to convert $\rho_{\mathrm{A}}^{\prime}$ into $\rho_{\mathrm{A}}$ by using statistical relations derived from solar radiation data collected from four solar radiation monitoring stations of Silpakorn University, which are located in the main regions of Thailand (see Figure 3). Details of these stations are given in Table 2 and the procedure for deriving the relations is explained as follows.

Firstly, the equation for calculating the broadband atmospheric transmittance (5) is rearranged to obtain the broadband atmospheric reflectivity as

$$
\begin{aligned}
\rho_{\mathrm{A}}= & \frac{\left(1-\rho_{\mathrm{aer}}\right)\left(1-\alpha_{\mathrm{o}}-\alpha_{\mathrm{w}}-\alpha_{\mathrm{aer}}\right)}{1-\alpha_{\mathrm{o}}-\alpha_{\mathrm{w}}-\alpha_{\mathrm{aer}}-\tau \rho_{\mathrm{G}}\left(1-\alpha_{\mathrm{o}}-\alpha_{\mathrm{w}}-\alpha_{\mathrm{aer}}\right)^{2}} \\
& -\frac{\tau\left(1-\rho_{\mathrm{G}}\right)\left(1-\alpha_{\mathrm{o}}-\alpha_{\mathrm{w}}-\alpha_{\mathrm{aer}}\right)^{2}}{1-\alpha_{\mathrm{o}}-\alpha_{\mathrm{w}}-\alpha_{\mathrm{aer}}-\tau \rho_{\mathrm{G}}\left(1-\alpha_{\mathrm{o}}-\alpha_{\mathrm{w}}-\alpha_{\mathrm{aer}}\right)^{2}} .
\end{aligned}
$$

In (6), the atmospheric transmittance $\tau$ was calculated by

$$
\tau=\frac{H}{H_{0}},
$$

where $H$ is monthly average daily global radiation and $H_{0}$ is monthly average daily extraterrestrial radiation. The values of $\mathrm{H}$ are obtained from the measurements at all four stations. The other parameters of (14) are estimated using the method described in the previous sections with the input data measured at all four stations.

Secondly, the values of the satellite band atmospheric albedo $\left(\rho_{\mathrm{A}}^{\prime}\right)$ are computed from (3) employing the satellitederived earth-atmospheric albedo $\left(\rho_{\mathrm{EA}}^{\prime}\right)$ and the other parameters at the four stations.

Thirdly, the values of the broadband atmospheric reflectivity $\left(\rho_{\mathrm{A}}\right)$ are plotted against those of the satellite band reflectivity. The results are shown in Figure 2.

Finally, the graphs in Figure 2 are fitted with empirical equation written as follows:

$$
\begin{gathered}
\text { for GMS } 4 \rho_{\mathrm{A}}=0.5963 \rho_{\mathrm{A}}^{\prime}+0.1882 R^{2}=0.75, \\
\text { for GMS5 } \rho_{\mathrm{A}}=0.9404 \rho_{\mathrm{A}}^{\prime}+0.1735 \quad R^{2}=0.73, \\
\text { for GOES9 } \rho_{\mathrm{A}}=0.8824 \rho_{\mathrm{A}}^{\prime}+0.1615 \quad R^{2}=0.84, \\
\text { for MTSAT-1R } \rho_{\mathrm{A}}=0.8795 \rho_{\mathrm{A}}^{\prime}+0.2380 \quad R^{2}=0.66,
\end{gathered}
$$

These empirical relations are used to convert $\rho_{\mathrm{A}}^{\prime}$ into $\rho_{\mathrm{A}}$ in the model validation and radiation mapping processes.

2.4. Model Validation. The technique used in this study relies on the satellite data and ground-based observations. A validation scheme which compares the satellite-derived solar radiation to the ground measurements is still needed prior to the generation of solar radiation maps. To accomplish this step, the models written in (2)-(6) are used to calculate solar radiation at 36 locations which have solar radiation monitoring stations. The values of solar radiation obtained from the models were then compared with the measurements at each station. The locations of these stations are shown in Figure 3, and their names, latitudes, longitudes, altitudes, and periods of data coverage are given in Table 3 . Note that the four stations (Table 2), whose data are used to establish the relationship between $\rho_{\mathrm{A}}$ and $\rho_{\mathrm{A}}^{\prime}$, are excluded from the model validation because they are involved in the model development. Therefore, solar radiation data from 36 stations are independent datasets.

Monthly average values of $\rho_{\mathrm{A}}$ and $\rho_{\mathrm{A}}^{\prime}$ are obtained at each station and they are further processed along with surface observations so as to estimate a monthly average of clearly solar radiation (6).

Comparisons of the values of long-term monthly average of satellite-derived daily solar radiation and the corresponding measurement data collected from 36 stations are carried out. The stations belong to the Department of Alternative Energy Development and Efficiency, Thailand. Solar radiation from these stations is measured by using pyranometers of Kipp \& Zonen (model CM11). 
TABLE 3: Names, latitudes, longitudes of measurement stations, and period of data. Also shown in this table are the values of root mean square different (RMSD) and mean bias difference (MBD) obtained from the comparison between the model and measured long-term monthly average daily radiations.

\begin{tabular}{|c|c|c|c|c|c|c|c|}
\hline No. & Stations & $\begin{array}{l}\text { Latitude } \\
\text { (Degree) }\end{array}$ & $\begin{array}{c}\text { Longitude } \\
\text { (Degree) }\end{array}$ & $\begin{array}{l}\text { Altitude } \\
(\mathrm{m})\end{array}$ & Period of data & RMSD (\%) & $\operatorname{MBD}(\%)$ \\
\hline 1 & Chiang Rai & 20.08 & 99.88 & 495 & Jan, 2002-Dec, 2009 & 7.1 & 3.7 \\
\hline 2 & Mae Hong Son & 19.43 & 97.96 & 730 & Jan, 2002-Dec, 2009 & 11.6 & 6.5 \\
\hline 3 & Doi Intanon (Mae Klang) & 18.40 & 98.67 & 564 & Mar, 2005-Dec, 2009 & 10.3 & 3.1 \\
\hline 4 & Nan & 18.72 & 100.75 & 459 & Jan, 2002-Dec, 2009 & 5.6 & -1.2 \\
\hline 5 & Chiang Mai (Sansai) & 18.83 & 98.88 & 565 & Jan, 2002-Dec, 2009 & 5.1 & -2.3 \\
\hline 6 & Mae Sa Riang & 18.17 & 97.93 & 698 & Jan, 2005-Dec, 2009 & 4.4 & -0.9 \\
\hline 7 & Phrae & 18.06 & 100.06 & 390 & Jan, 2005-Dec, 2009 & 4.6 & -1.9 \\
\hline 8 & Tak & 16.80 & 98.90 & 562 & Jan, 2002-Dec, 2009 & 7.9 & -1.8 \\
\hline 9 & Loei & 17.40 & 101.00 & 492 & Apr, 2005-Dec, 2009 & 4.0 & -0.5 \\
\hline 10 & Nong Khai & 17.87 & 102.72 & 177 & Jan, 2002-Dec, 2009 & 3.7 & -0.8 \\
\hline 11 & Khon Kaen & 16.45 & 102.78 & 179 & Feb, 2002-Dec, 2009 & 4.1 & -0.4 \\
\hline 12 & Nakhon Panom & 16.97 & 104.73 & 184 & Jan, 2002-Dec, 2009 & 5.1 & 1.7 \\
\hline 13 & Surin & 14.88 & 103.50 & 162 & Jan, 2002-Dec, 2009 & 2.7 & 0.1 \\
\hline 14 & Ubon Ratchathani (Agr. Met) & 15.28 & 105.14 & 160 & Jan, 2002-Dec, 2009 & 3.7 & 1.5 \\
\hline 15 & Nakhon Ratchasima & 14.97 & 102.08 & 218 & Jan, 2002-Dec, 2009 & 2.6 & 0.6 \\
\hline 16 & Roi Et & 16.07 & 103.00 & 153 & Mar, 2006-Dec, 2009 & 5.8 & -5.0 \\
\hline 17 & Phitsanulok & 16.78 & 100.27 & 137 & Jan, 2002-Dec, 2009 & 3.6 & -1.3 \\
\hline 18 & Phetchabun & 16.43 & 101.15 & 250 & Jan, 2002-Dec, 2009 & 3.3 & -0.6 \\
\hline 19 & Nakhon Sawan & 15.67 & 100.12 & 50 & Jan, 2002-Dec, 2009 & 3.1 & 0.6 \\
\hline 20 & Lop Buri & 14.83 & 100.62 & 54 & Jan, 2002-Dec, 2009 & 3.6 & 0.4 \\
\hline 21 & Bangkok & 13.75 & 100.52 & 2 & Apr, 2002-Dec, 2009 & 7.4 & 6.6 \\
\hline 22 & Kanchanaburi (Muang) & 14.02 & 99.53 & 159 & Jan, 2005-Dec, 2009 & 3.8 & -0.7 \\
\hline 23 & $\begin{array}{l}\text { Kanchanaburi } \\
\text { (Thong Pha Phum) }\end{array}$ & 14.73 & 98.63 & 345 & Jan, 2002-Dec, 2009 & 2.9 & -0.2 \\
\hline 24 & Sa Kaeo (Aranyaprathet) & 13.70 & 102.00 & 62 & Jan, 2007-Dec, 2009 & 4.7 & 2.6 \\
\hline 25 & Trat & 11.77 & 102.88 & 68 & Mar, 2006-Dec, 2009 & 5.1 & -0.7 \\
\hline 26 & Prachin Buri & 13.97 & 101.70 & 46 & Jan, 2002-Dec, 2009 & 2.8 & -1.3 \\
\hline 27 & Chon Buri & 13.37 & 100.97 & 5 & Mar, 2005-Dec, 2009 & 4.4 & -0.5 \\
\hline 28 & Prachuap Khiri Khan & 11.83 & 99.83 & 1 & Feb, 2002-Dec, 2009 & 5.3 & 2.6 \\
\hline 29 & Chumphon & 10.40 & 99.18 & 8 & Mar, 2005-Dec, 2009 & 9.8 & 7.6 \\
\hline 30 & Ranong & 9.98 & 98.62 & 34 & Jan, 2002-Dec, 2009 & 2.4 & 1.7 \\
\hline 31 & Surat Thani (Samui) & 9.47 & 100.05 & 1 & Jan, 2002-Dec, 2009 & 3.6 & 1.1 \\
\hline 32 & Surat Thani (Punpin) & 9.13 & 99.15 & 10 & Apr, 2005-Dec, 2009 & 5.3 & 0.7 \\
\hline 33 & Phuket & 8.13 & 98.30 & 26 & Jan, 2002-Dec, 2009 & 6.4 & -5.0 \\
\hline 34 & Trang & 7.52 & 99.62 & 55 & Mar, 2005-Dec, 2009 & 5.0 & -0.2 \\
\hline 35 & Songkhla (Hadyai) & 6.92 & 100.43 & 53 & Jan, 2002-Dec, 2009 & 4.3 & 0.3 \\
\hline \multirow[t]{2}{*}{36} & Narathiwat & 6.40 & 101.82 & 8 & Feb, 2002-Dec, 2009 & 4.4 & -1.6 \\
\hline & Combined data & & & & & 5.3 & 0.3 \\
\hline
\end{tabular}

*As the comparison is based on the long-term monthly average values, the total number of data used to calculate RMSD and MBD are equal to 12.

The relative root mean square difference (RMSD) and relative mean bias difference (MBD) are used to assess the performance of the model. The RMSD and MBD are defined as follows:

$$
\begin{aligned}
\operatorname{RMSD} & =\frac{\sqrt{\left(\sum_{i=1}^{N}\left(H_{\text {model }, i}-H_{\text {meas }, i}\right)^{2}\right) / N}}{\left(\sum_{i=1}^{N} H_{\text {meas }, i}\right) / N} \times 100 \%, \\
\operatorname{MBD} & =\frac{\left(\sum_{i=1}^{N}\left(H_{\text {model }, i}-H_{\text {meas }, ~}\right)\right) / N}{\left(\sum_{i=1}^{N} H_{\text {meas }, i}\right) / N} \times 100 \%,
\end{aligned}
$$

where $H_{\text {model }, i}$ and $H_{\text {meas }, i}$ are the calculated and measured long-term monthly average radiation of the $i$ th month, respectively, and $N$ is the total months of the year. In order to obtain the long-term average radiation of a month, both from the measurements and model, the values of radiation of that month are averaged over the period of the data. The results of the comparisons are shown in Table 3.

It is observed that values of RMSD and MBD are in the range of $2.4-11.6 \%$ and $-0.2-6.5 \%$, respectively. When all data are combined, the RMSD and MBD are 5.3\% and $0.3 \%$, respectively. The original model [24] gives the RMSD and $\mathrm{MBD}$ of $6.8 \%$ and $2.7 \%$, respectively. This indicates 


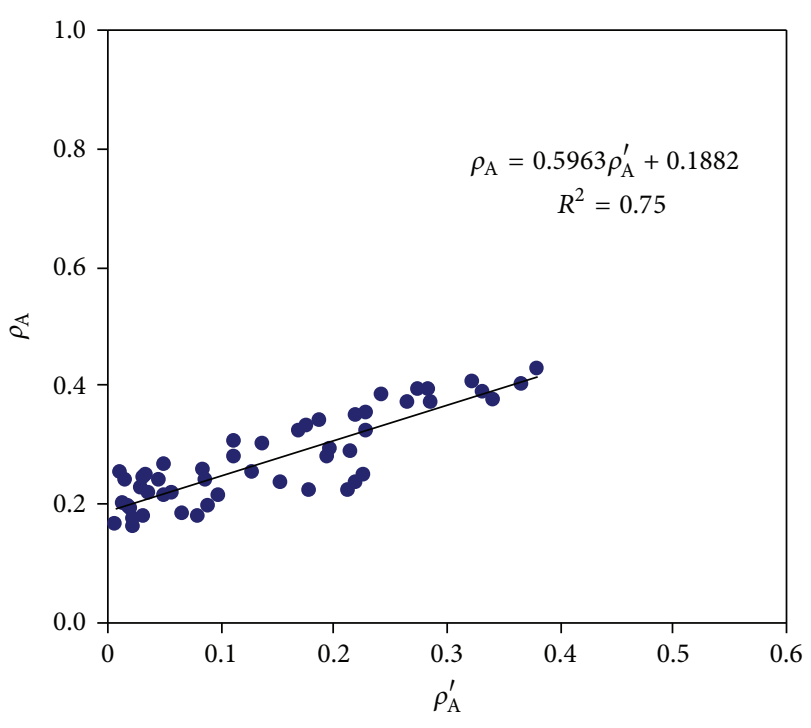

(a)

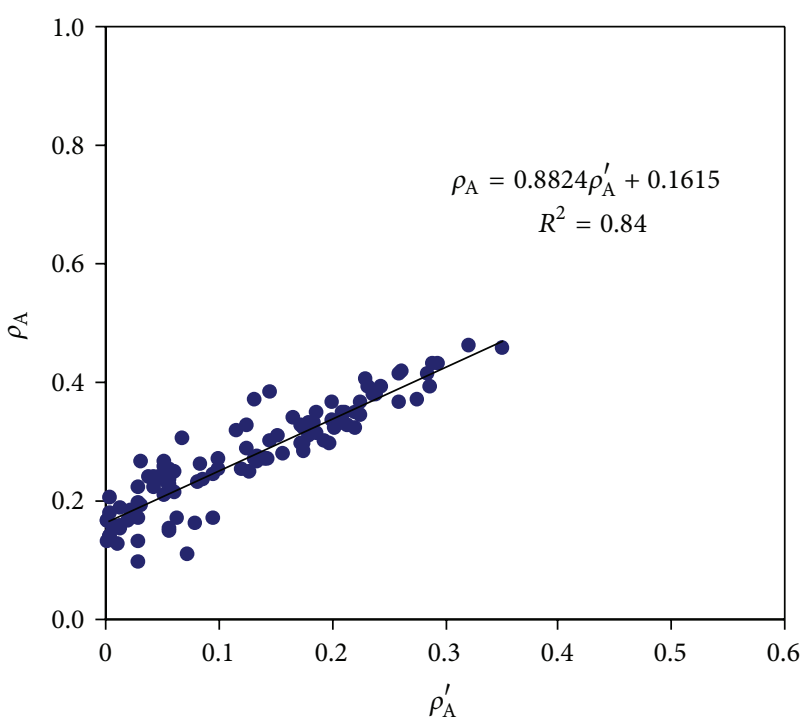

(c)



(b)



(d)

FIGURE 2: Relation between the broadband atmospheric reflectivity $\left(\rho_{\mathrm{A}}\right)$ and satellite band atmospheric reflectivity $\left(\rho_{\mathrm{A}}^{\prime}\right)$ for: (a) GMS4 (b) GMS5, (c) GOES9 and (d) MTSAT-1R. ( $R$ is the correlation coefficient).

thatthe improved model provides more accurate results than those of the original model.

\section{Result and Discussion}

After the validation, the model is used to generate the solar radiation maps of Thailand. The calculation is carried out for all arrays of $500 \times 800$ pixels covering the entire area of Thailand. The results are averaged to obtain values of longterm monthly and yearly average daily solar radiation. Then they are displayed as monthly and yearly maps in Figures 4 and 5 , respectively.

From the monthly maps (Figure 4), it is observed that solar radiation increases from January to February. This is because the sun path progressively moves northward to the celestial equator during this period, causing an increase of solar radiation in most parts of the country. It can also be seen that solar radiation in most parts of the south is higher than that of the north due to the effect of the sun path. Cloudiness is not a dominant effect because these two months are in the period of the northeast monsoon with the majority of clear sky days, except in the mountainous areas.

In March and April, high solar radiation ofover $18 \mathrm{MJ} / \mathrm{m}^{2}$ day features in most parts of the country. High solar radiation of more than $20 \mathrm{MJ} / \mathrm{m}^{2}$-day is observed over large parts of the east and the south of Thailand. This is because solar radiation at noon time is almost perpendicular to the earth surface over the country. For example, on the 1st of April the values of solar zenith angle at Narathiwat $\left(6.40^{\circ} \mathrm{N}, 101.82^{\circ} \mathrm{E}\right)$, Bangkok $\left(13.75^{\circ} \mathrm{N}, 100.52^{\circ} \mathrm{E}\right)$, and Chiang Rai $\left(20.08^{\circ} \mathrm{N}, 99.88^{\circ} \mathrm{E}\right)$ are 




FIGURE 3: Positions of solar radiation monitoring stations where solar radiation data are used for the model validation (red circle). Positions of the stations where solar radiation data are employed to relate $\rho_{\mathrm{A}}$ with $\rho_{\mathrm{A}}^{\prime}$ (blue triangle) $\mathrm{A}, \mathrm{B}, \mathrm{C}$ and $\mathrm{D}$ indicate the main regions namely, the northern region, northeastern region, central region and the southern region.

$2.16^{\circ}, 9.56^{\circ}$, and $15.70^{\circ}$, respectively (see Figure 3 ). In addition, these two months correspond to the transition period between the northeast and the southwest monsoons with numerous clear sky days.

In general, the onset of the southwest monsoon is in May, causing cloudy skies over areas in the south and the east of Thailand. Consequently, low solar radiation (14-17 MJ/m² day) values are observed in these areas. High solar radiation of $18-20 \mathrm{MJ} / \mathrm{m}^{2}$-day still features in the north because these areas are less exposed to this monsoon. Values of 20$22 \mathrm{MJ} / \mathrm{m}^{2}$-day are observed in the central region.

From June to October, solar radiation decreases for most parts of the country due to high cloudiness and rainfall caused by the enhancement of the southwest monsoon, despite the higher extraterrestrial solar radiation in this period.

In general, the monsoon changes from the southwest to northeast monsoons in mid-October and the northeast monsoon brings dry and cool air to most parts of the country, 

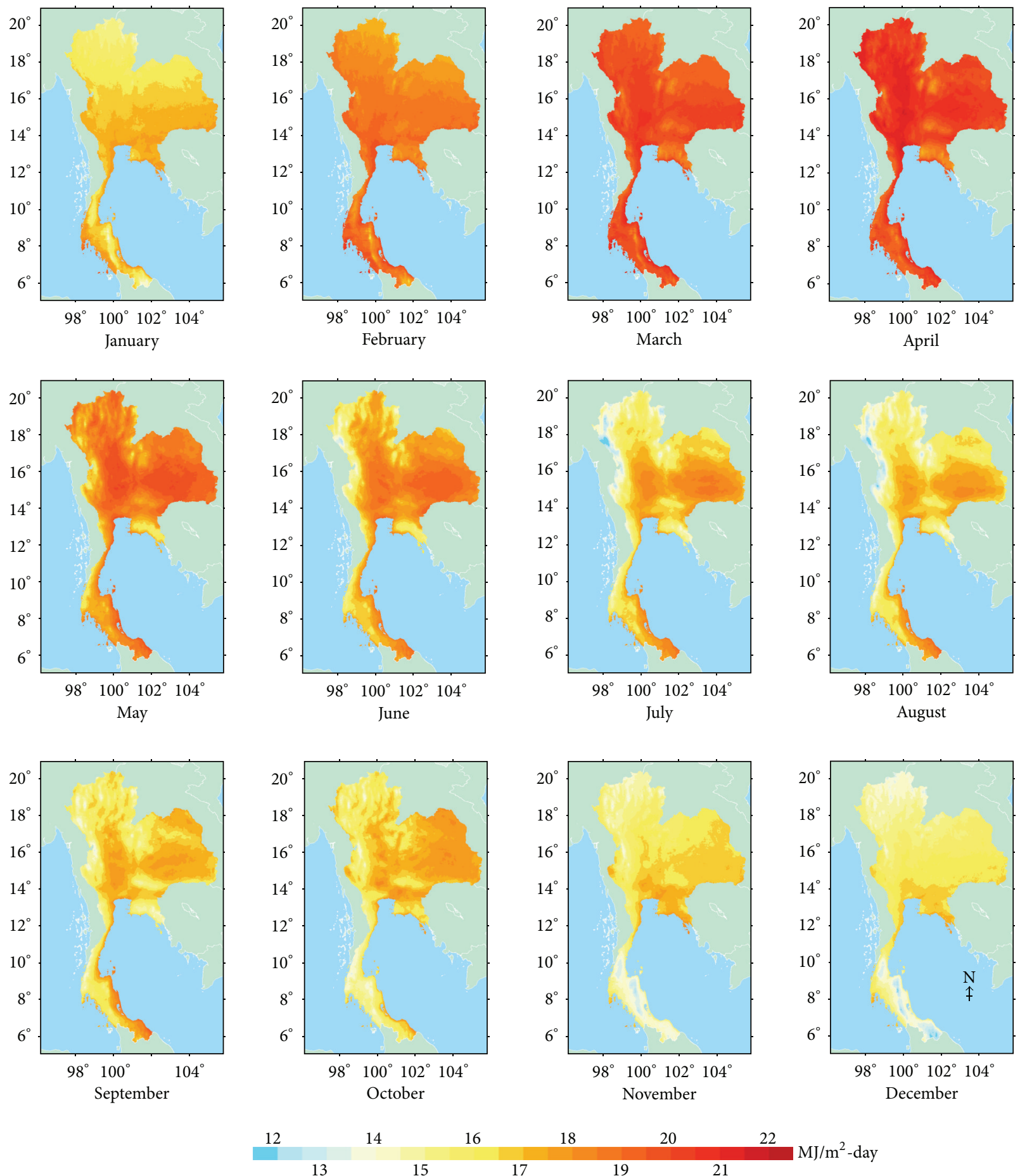

FIGURE 4: Monthly average of daily global radiation over Thailand.

causing clearer sky, except for the south. This is because the monsoon blows across the Gulf of Thailand (see Figure 3) bringing moisture to the south which results in rainfall and cloudy skies. The effect of this monsoon continues to December, causing low solar radiation in the south. Although, the rest of the country is mostly under clear sky condition, the sun path moves southward from the celestial equator, causing low extraterrestrial radiation and consequently lowing surface solar radiation.

On a yearly basis (Figure 5), the map demonstrates geographical distribution of average solar radiation caused by all factors affecting solar radiation in each month. The main factors include the variation of the sun path, monsoons, and local geographical features. The combined effects of these 


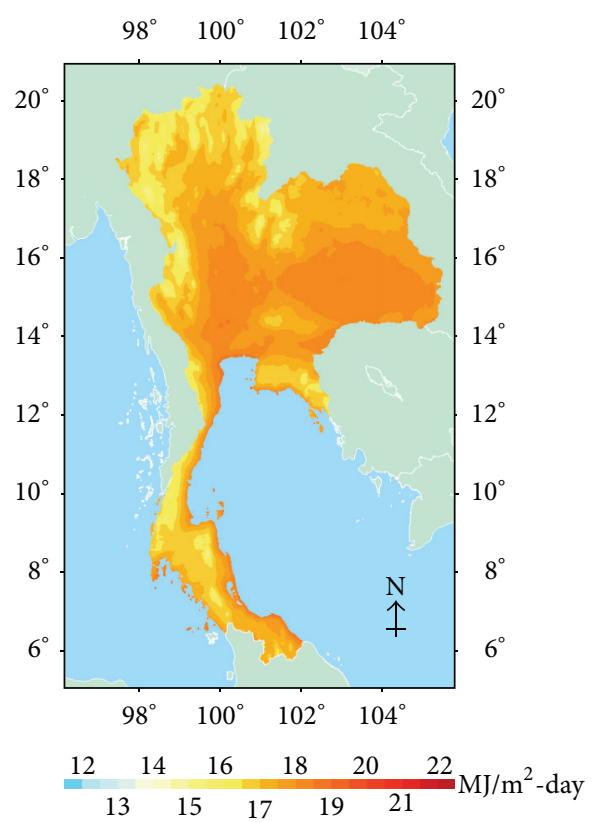

FIGURE 5: Yearly average of daily global radiation over Thailand.

factors resulted in patterns of solar radiation distribution. From these patterns, it is noticed that the areas which receive the highest solar radiation are mainly in the high plain of the northeast region and the low plain of the central region of the country. The areas which receive less solar radiation are in the mountainous areas in the northern region and western parts of the country.

\section{Conclusion}

A technique for mapping solar radiation in the tropics has been presented. In mapping solar radiation a satellite-based solar radiation model has been improved. The improved model was validated against solar radiation measured at 36 solar monitoring stations in Thailand. It was found that solar radiation calculated from the model and that obtained from the measurements were in good agreement, with the discrepancy in terms of root mean square difference and mean bias difference of $5.3 \%$ and $0.3 \%$, respectively. The improved model performed better than the original model. The improved model was subsequently used to map solar radiation over the entire country. Results reveal that geographical distribution of solar radiation in this region depends strongly on the tropical monsoons and local geographical features.

\section{Acknowledgment}

The authors would like to thank the Department of Alternative Energy Development and Efficiency, Ministry of Energy of Thailand, for inviting Silpakorn University to carry out this work.

\section{References}

[1] J. D. Tarpley, "Estimating incident solar radiation at the surface from geostationary satellite data," Journal of Applied Meteorology, vol. 18, no. 9, pp. 1172-1181, 1979.

[2] C. Gautier, G. Diak, and S. Masse, "A simple physical model to estimate incident solar radiation at the surface from GOES satellite data," Journal of Applied Meteorology, vol. 19, no. 8, pp. 1005-1012, 1980.

[3] W. Moser and E. Raschke, "Incident solar radiation over Europe estimated from Meteosat data," Journal of Climate \& Applied Meteorology, vol. 23, no. 1, pp. 166-170, 1984.

[4] M. Nunez, T. L. Hart, and J. D. Kalma, "Estimating solar radiation in a tropical environment using satellite data," Journal of Climatology, vol. 4, no. 6, pp. 573-585, 1984.

[5] R. H. B. Exell, "Mapping solar radiation by meteorological satellite," Renewable Energy Review Journal, vol. 6, no. 1, 1984.

[6] D. Cano, J. M. Monget, M. Albuisson, H. Guillard, N. Regas, and L. Wald, "A method for the determination of the global solar radiation from meteorological satellite data," Solar Energy, vol. 37, no. 1, pp. 31-39, 1986.

[7] G. Dedieu, P. Y. Deschamps, and Y. H. Kerr, "Satellite estimation of solar irradiance at the surface of the earth and of surface albedo using a physical model applied to Meteosat data," Journal of Climate \& Applied Meteorology, vol. 26, no. 1, pp. 79-87, 1987.

[8] M. Nunez, W. J. Skirving, and N. R. Viney, "A technique for estimating regional surface albedos using geostationary satellite data," Journal of Climatology, vol. 11, pp. 100-120, 1987.

[9] C. Sorapipatana, R. H. B. Exell, and D. Borel, "A bispectral method for determining global solar radiation from meteorological satellite data," Solar and Wind Technology, vol. 5, no. 3, pp. 321-327, 1988.

[10] C. Sorapipatana and R. H. B. Exell, "Mesoscale mapping of daily insolation over Southest Asia from satellite data," Solar and Wind Technology, vol. 6, no. 1, pp. 59-69, 1989.

[11] L. Diabaté, G. Moussu, and L. Wald, "Description of an operational tool for determining global solar radiation at ground using geostationary satellite images," Solar Energy, vol. 42, no. 3, pp. 201-207, 1989.

[12] H. G. Beyer, C. Costanzo, and D. Heinemann, "Modifications of the heliosat procedure for irradiance estimates from satellite images," Solar Energy, vol. 56, no. 3, pp. 207-212, 1996.

[13] J. Hirunlabh, R. Sarachitti, P. Namprakai et al., "Estimating solar radiation at the earth's surface from satellite data," Tammasart International Journal of Science and Technology, vol. 1, pp. 8997, 1997.

[14] P. Ineichen and R. Perez, "Derivation of cloud index from geostationary satellites and application to the production of solar irradiance and daylight illuminance data," Theoretical and Applied Climatology, vol. 64, no. 1-2, pp. 119-130, 1999.

[15] K. Wyser, W. O’Hirok, C. Gautier, and C. Jones, "Remote sensing of surface solar irradiance with corrections for 3-D cloud effects," Remote Sensing of Environment, vol. 80, no. 2, pp. 272-284, 2002.

[16] M. Nunez, "The development of a satellite-based insolation model for the tropical western Pacific Ocean," International Journal of Climatology, vol. 13, no. 6, pp. 607-627, 1993.

[17] C. Schillings, H. Mannstein, and R. Meyer, "Operational method for deriving high resolution direct normal irradiance from satellite data," Solar Energy, vol. 76, no. 4, pp. 475-484, 2004. 
[18] F. Vignola, P. Harlan, R. Perez, and M. Kmiecik, "Analysis of satellite derived beam and global solar radiation data," Solar Energy, vol. 81, no. 6, pp. 768-772, 2007.

[19] E. Cogliani, P. Ricchiazzi, and A. Maccari, "Physical model SOLARMET for determinating total and direct solar radiation by meteosat satellite images," Solar Energy, vol. 81, no. 6, pp. 791798, 2007.

[20] J. Polo, L. F. Zarzalejo, M. Cony et al., "Solar radiation estimations over India using Meteosat satellite images," Solar Energy, vol. 85, pp. 2395-2406, 2011.

[21] N. Lu, J. Qin, K. Yang, and J. Sun, "A simple and efficient algorithm to estimate daily global solar radiation from geostationary satellite data," Energy, vol. 36, no. 5, pp. 3179-3188, 2011.

[22] M. Journée, R. Müller, C. Bertrand et al., "Solar resource assessment in the Benelux by merging Meteosat-derived climate data and ground measurements," Solar Energy, vol. 86, pp. 35613574, 2012.

[23] J. L. Bosch, F. J. Batlles, L. F. Zarzalejo, and G. López, "Solar resources estimation combining digital terrain models and satellite images techniques," Renewable Energy, vol. 35, no. 12, pp. 2853-2861, 2010.

[24] S. Janjai, J. Laksanaboonsong, M. Nunez, and A. Thongsathitya, "Development of a method for generating operational solar radiation maps from satellite data for a tropical environment," Solar Energy, vol. 78, no. 6, pp. 739-751, 2005.

[25] M. Iqbal, An Introduction to Solar Radiation, Academic Press, New York, NY, USA, 1983.

[26] ASTM, Standard Solar Constant and Zero Air Mass Solar Spectral Table. Standard E-490-00 American Society for Testing and materials, West Conshohocken, Pa, USA, 2000.

[27] E. F. Vermote, D. Tanrè, J. L. Deuzè, M. Herman, and J. J. Morcrette, "Second simulation of the satellite signal in the solar spectrum, 6S: an overview," IEEE Transactions on Geoscience and Remote Sensing, vol. 35, pp. 675-686, 1997.

[28] S. Janjai, W. Wanvong, and J. Laksanaboonsong, "The determination of surface albedo of Thailand using satellite data," in Proceedings of the 2nd Joint International Conference on Sustainable Energy and Environment (SEE '06), pp. 156-161, Bangkok, Thailand, 2006.

[29] B. Leckner, "The spectral distribution of solar radiation at the earth's surface-elements of a model," Solar Energy, vol. 20, no. 2, pp. 143-150, 1978.

[30] K. Chiwpreecha and S. Janjai, "An investigation of the atmospheric ozone in Thailand," in Proceedings of the Annual Conference of Silpakorn University Research and Development Institute, Silpakorn University, Nakhon Pathom, Thailand, January 2010.

[31] T. Jantarach, I. Masiri, and S. Janjai, "Comparison of MODIS aerosol optical depth retrievals with ground-based measurements in the tropics," Procedia Engineering, vol. 32, pp. 392-398, 2012. 

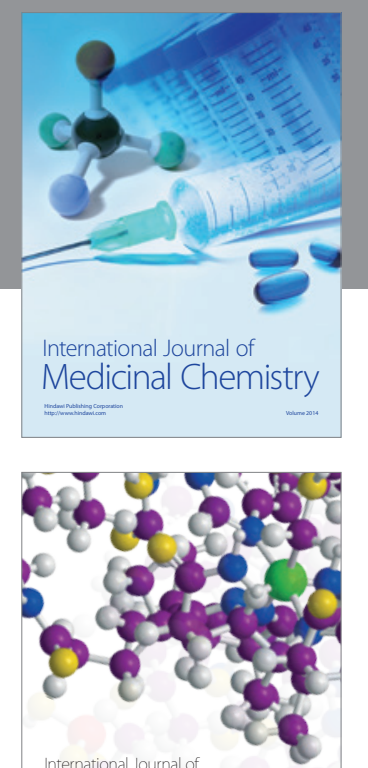

\section{Carbohydrate} Chemistry

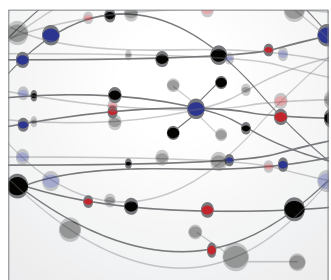

The Scientific World Journal
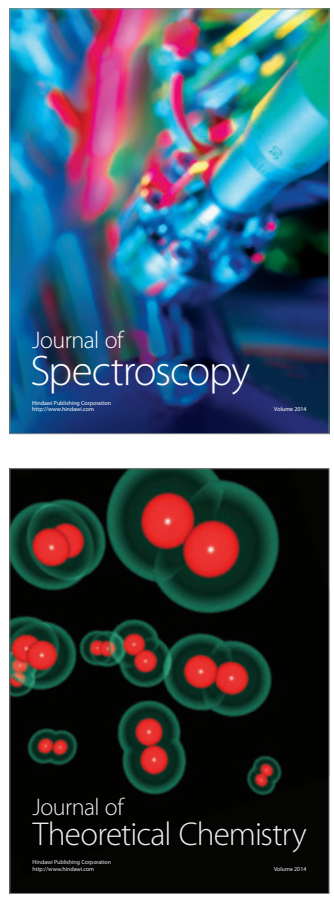
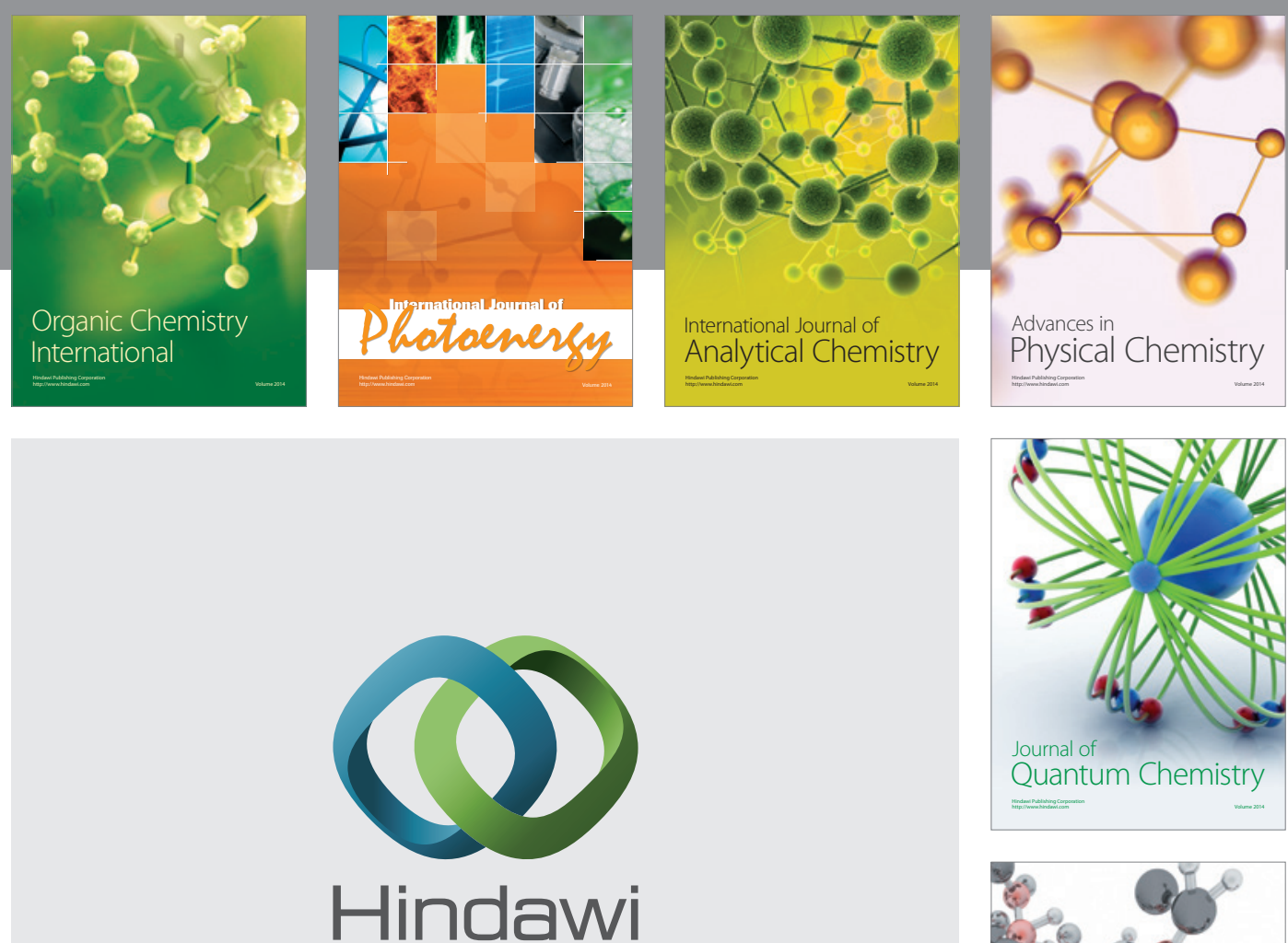

Submit your manuscripts at

http://www.hindawi.com

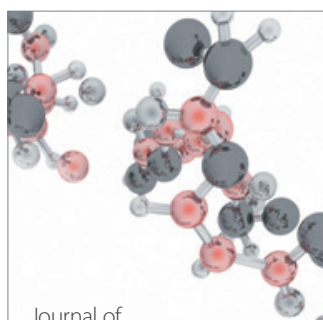

Analytical Methods

in Chemistry

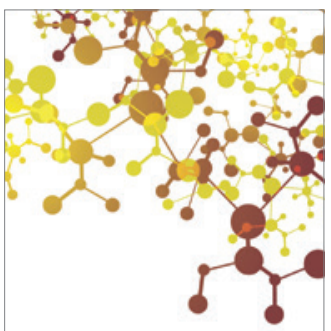

Journal of

Applied Chemistry

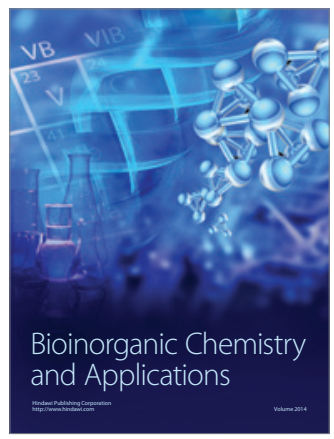

Inorganic Chemistry
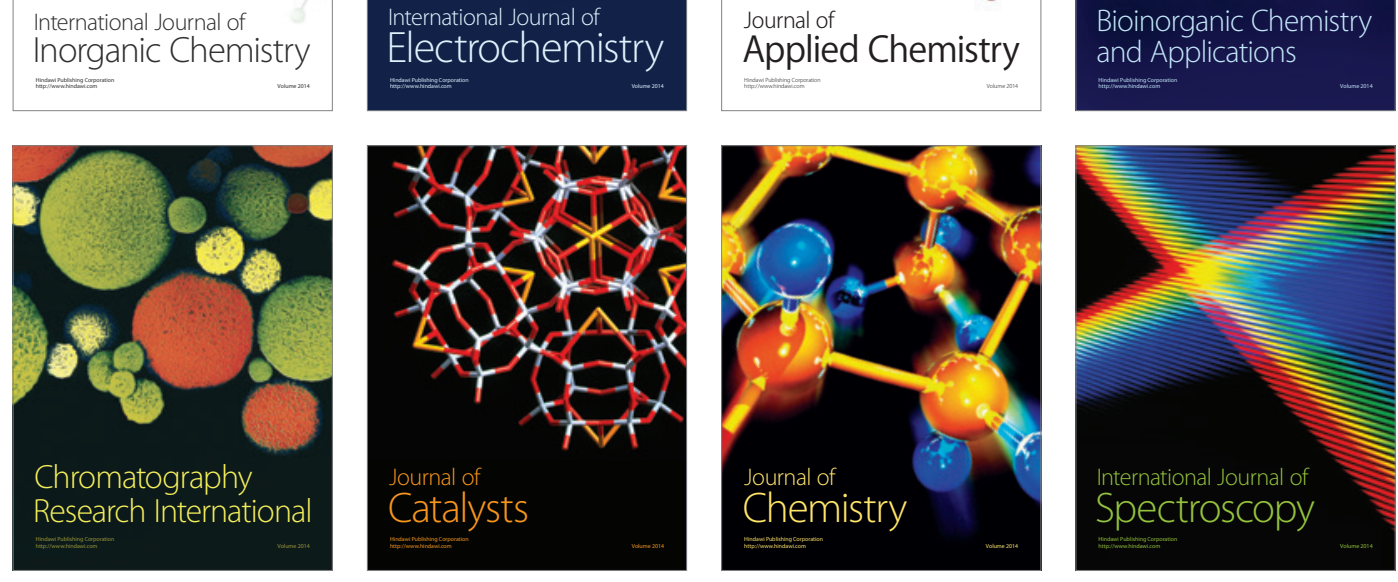